\title{
PERSEPSI KELOMPOK DISABILITAS MENTAL TERHADAP \\ PERILAKU SEKSUAL DI SLBN PEKKABATA POLEWALI MANDAR SULAWESI BARAT
}

\author{
Hadriyani Amin' ${ }^{1}$ Andi Multazam², Een Kurnaesih ${ }^{3}$
}

Alamat Korespondesi : honeyamin31@gmail.com/085255928819

\begin{abstract}
ABSTRAK
Perilaku seksual kelompok remaja dengan disabilitas mental penting untuk dikaji karena remaja disabilitas mental merupakan kelompok yang rentan mengalami pelecehan seksual dan melakukan perilaku seksual yang menyimpang. Tujuan penelitian bertujuan untuk mengetahui persepsi kelompok disabilitas mental terhadap perilaku seksual di SLBN pekkabata polewali mandar Sulawesi barat. Digunakan Metode Kualitatif dengan pendekatan wawancara secara mendalam. Informan penelitian ini sebanyak delapan orang yang terdiri dari informan biasa lima orang, informan pendukung dua orang dan informan kunci satu orang.Hasil penelitian ini menunjukkan bahwa : (1) pengetahuan kelompok disabilita mental semakin tinggi pengetahun kesehatan reproduksi semakin rendah perilaku seksual pranikahnya; (2) sikap disabilitas semakin positif dan sikap remaja terhadap perilakunya semakin besar dengan intensitasnya untuk melakukan perilaku seksual; (3) tindakan penyandang disabilitas dalam hal aktivitas fisik, tidak menyentuh bagian intim; (4) perilaku seksual sangat beragam, pemicunya bisa karena pengaruh lingkungan,sosial budaya, penghayatan kegamaan , serta penerapan nilai-nilai; (5) aktivitas sosial berisiko belum paham tentang bahaya dari perilaku yang tidak normal. Disarankan agar penyandang disabilitas lebih maksimal menjaga kesehatan reproduksi dan sebaiknya pekerja sosial mengadakan penyuluhan tentang kesehatan reproduksi remaja, agar lebih meningkatkan pengetahuan, sikap dan perilakunya.
\end{abstract}

Kata Kunci $\quad$ : Disabilitas Mental, Remaja, Perilaku Seksual, Kesehatan Reproduksi.

\section{PENDAHULUAN}

Masa remaja adalah masa transisi, dimana pada masa seperti ini sering terjadi ketidakstabilan emosi maupun jiwa. Pada masa transisi ini remaja juga sedang mencari jati dirinya dan menjadi sebuah fase dimana seseorang akan mengalami peralihan dan perubahan tahap dari segi emosi, tubuh, minat dan perilaku. Pada fase ini, kondisi perilaku remaja menunjukkan masalah yang makin mengkhawatirkan khususnya masalah Kesehatan Reproduksi Remaja (KRR) pada sisiwa Sekolah Menengah Atas (SMA), seperti penggunaan obatobatan terlarang, perilaku seks pranikah, kehamilan tak diinginkan (KTD) dan Infeksi Menular Seks (IMS) (Nirmaya Mariani, N \& Fitriani Arsy, D, 2017 ; Hermiyanti, dkk, 2016).

Badan Koordinasi Keluarga Berencana Nasional (BKKBN) mengemukakan tiga resiko atau masalah kesehatan reproduksi remaja yang akan sering dihadapi oleh kaum remaja adalah NAPZA, HIV/AIDS dan seksualitas yang biasa disebut dengan TRIAD KRR. Permasalahan tersebut umumnya muncul dari ketidaktahuan siswa terhadap perkembangan fisik yang dialaminya ketika menginjak masa remaja, sementara ketersediaan informasi yang tepat masih sangat minim baik di sekolah maupun lingkungan keluarga (Hermiyanti, dkk, 2016).

Perilaku seksual kelompok remaja dengan disabilitas mental penting untuk dikaji karena remaja disabilitas mental merupakan kelompok yang rentan mengalami pelecehan seksual dan melakukan perilaku seksual yang menyimpang. Perkembangan seksual remaja disabilitas mental tidak berbeda dengan remaja awam pada umumnya. Perkembangan perilaku seksual remaja seringkali tidak dipahami dengan benar oleh keluarga, guru, teman dan lingkungan sosial lainnya. Perlindungan sosial remaja disabilitas mental yang longgar, membuat situais remaja disabilitas mental menjadi semakin rawan dimanfaatkan oleh pedofil dan orang-orang yang memiliki kesehatan mental yang terganggu (Farakhiyah, R, 2018).

World Health Organisation (WHO)menyebutkan bahwa jumlah penyandang disabilitas di Indonesia mencapai 10 juta jiwa, sementara rata-rata jumlah penyandang disabilitas 
di negara berkembang sebesar $10 \%$ dari total populasi penduduk. Sedangkan Kementrian Sosial RI, pada tahun 2011 mengemukakan, jumlah penyandang disabilitas di Indonesia mencapai $3,11 \%$, atau sebesar 6,7 juta jiwa (Farakhiyah, R, 2018).

Berdasarkan beberapa hasil penelitian terdahulu dan yang dijelaskan di atas, disimpulkan bahwa Pemahaman dan pengetahuan remaja terhadap kesehatan reproduksi dan seksualitas selama ini terbilang masih rendah dan tidak sedikit pula yang mengabaikannya. Hal ini dapat berefek pada risiko seksual yang dihadapi oleh remaja sehingga Pendidikan seks bagi anak berkebutuhan khusus kini menjadi sebuah kebutuhan.

Banyak anak penyandang cacat yang memiliki akses rendah terhadap informasi kesehatan bahkan informasi dasar tentang bagaimana tubuh mereka berkembang dan berubah. Selain itu mereka sering diajarkan untuk diam dan patuh sehingga sangat berisiko mendapat tindak kekerasan dan pelecehan seksual. (Unicef, 2013).

\section{BAHAN DAN METODE}

\section{Desain dan variable penelitian}

Jenis penelitian ini adalah analisis deskriptif dengan menggunakan metode kualitatif yaitu mengeksplorasi secara mendalam mengenai persepsi kelompok disabilitas mental terhadap perilaku seksualitas di SLBN polewali mandardengan caramelalui wawancara mendalam (indepth interview) dan pengamatan (observasi) secara terus menerus.

\section{Lokasi dan Waktu Penelitian}

Penelitian ini akan dilaksanakan di SLBN Pekkabata Polman Sulawesi Barat. Penelitian ini akan dilaksanakan pada bulan 03 oktober - 03 november tahun 2018.

\section{Populasi dan sampel}

Dalam penelitian ini yang menjadi subyek penelitian adalah kelompok disabilitas mental. Dengan informan pendukung yaitu guru dan kepala sekolah SLBN polewali mandar Sulawesi barat. Pemilihan informan pada penelitian ini menggunakan Snowball sampling. Berikut adalah pemaparan mengenai informan dalam penelitian ini yaitu Informan utama 30 orang, Informan Pendukung 25 orang, dan Informan Kunci 20 orang.
Metode pengumpulan data

Data primer yaitu data yang didapat lansung dari penelitian. Sumber data primer yang digunakan dalam penelitian ini meliputi Kelompok Disabilitas Mental, Guru dan Kepala Sekolah, Orang tua dan Keluarga. Data sekunder yaitu data yang diperoleh dari SLBN polewali mandar, data sekunder juga digunakan sebagai data pelengkap untuk data primer yang berhubungan dengan masalah yang diteliti seperti jumlah keseluruhan sampel dan responden di SLBN polewali mandar. Dalam penelitian ini sumber data sekunder yang dipakai adalah sumber tertulis seperti sumber buku, majalah ilmiah dan dokumen.

Analisa data

analisis data penelitian ini merujuk pada prosedur miler dan Huberman dalam Basrowi dan Suwandi (2009), yaitu Reduksi Data, Display Data, Menarik Kesimpulan/Verifikasi.

\section{HASIL PENELITIAN}

Profil tiap informan menjadi penting untuk digali lebih dalam sebab informasi apapun yang didapatkan dari informan bisa menjadi bahan penting yang mungkin terkait dengan penelitian. Berdasarkan karakteristik informan dapat digambarkan sebagai berikut.

Informan $M A$

"Informan MA berumur 15 tahun jenis kelamin laki laki merupakan anak tunggal dan tinggal bersama orang tua yang beralamat di kota polewali dan dari keluarga sederhana, diberikan kebijakan dari sekolah untuk tetap sekolah di SLBN, informan bersikap emosional namun respon informan cukup baik dan bisa di ajak komunikasi dengan baik, beragama islam, suku mandar, informan menyelesaikan pendidikan SMP, pekerjaan pelajar. Berdasarkan informasi informan sudah mengetahui apa itu lawan jenis dan mampu membedakan siapa saja yang merupakan lawan jenisnya".

"Hal tersebut dibuktikan pada saat wawancara, responden menunjuk kearah peneliti (perempuan) dan ke arah temantemannya (laki-laki). Informan pernah meraba alat vital sendiri tetapi tidak dilakukan pada teman atau orang lain, informan pun pernah mendengar nama alat kontrasepsi (kondom) tetapi tidak pernah melihat secara langsung. Informan juga secara tidak sengaja pernah menonton film tentang seks di 
handphone dan membaca di buku majalah dewasa, kemudian informan sudah tahu bahaya hubungan diluar nikah dan mengatakan bahwa tidak boleh melakukan bila belum berkeluarga ".

Hasil wawancara yang didapatkan dan informasi yang telah terkumpul dari informan mengatakan hal yang terkait tentang persepsi kelompok disabilitas terhadap perilaku seksualitas :

“...Saya memperoleh informasi mengenai perilaku seksual dari handphone ku biasa saya main hp pas pulang sekolah dan malam santai santai depan rumah sambil cari apakah begitu yang ada di dalam hp, bisa lihat yang indah dan cantik - cantik eehhh dan biasaka juga cari tahu dari teman- teman mainku yang diluar sekolah mereka itu aduh jago sekali dapatkan foto cewe cewe cantik dan sexy tapi tidak mi kemarin karena capek sekalika pulang dari samarinda ikut lomba keterampilan" (MA, 15 Tahun, 12.10.2018)

Pengetahuan adalah hasil penginderaan manusia, atau hasil tahu seseorang terhadap objek melalui indra yang dimilikinya (mata, hidung, telinga dan sebagainya). Dengan sendirinya pada waktu penginderaan sehingga menghasilkan pengetahuan tersebut sangat dipengaruhi oleh intensitas perhatian dan persepsi terhadap objek. Sebagian besar pengetahuan seseorang diperoleh melalui indra pendengaran (telinga), dan indra penglihatan (mata).

Berdasarkan pernyataan informan tersebut maka 8 informan mengatakan hal yang terkait tentang pengetahuan perilaku seksual dibawah ini :

“....Saya sudah ketahui jenis kelaminku kapank dari kecil karena di ajar oleh orang tua, saya pernah memegang anuku waktu kapan itu die kemudian informan terdiam saat ditanya lebih dalam dan sambil bercanda, kutauji akibatnya hubungan seksual, sadarma tidak kayak dulu lagi sambil tertawa terbahak bahak dan pandangan mata tidak focus lagi kearah peneliti, kenapa ka mau ти tau semua begituan ta, sembarang sekali dipertanyakan yang penting apa mu bikin kalau pacaran itu juga ku lakukan hahaha, selalu ka itu saya berkelahi suka suka kukasih menangis teman ku kalau ada lagi kasih jengkel ka pukul I, tapi tidak pernah ji ku pukul pacarku kusayang saying I dia kalau cewek ku...(MA.15 tahun, 12.10.2018)"

Berdasarkan pernyataan Informan tersebut maka 8 Informan tersebut mengatakan hal yang terkait dengan Sikap pada disabilitas tuna laras yang susah mengendalikan emosi atas nama MA mengatakan bahwa :

“... saya biasa ma dari dulu pacaran pernah itu ada pacarku datang kerumah bawwakan ka makanan, biasa juga saya kerumahnya bawakan makanan karena dia tinggal sama tantenya hanya berdua, orang tua nya tinggal di daerah mammi jauh dari sini, baru baru ini sy kasih putus cewekku krn ada lagi cewek baru ku kenal sambil tertawa terbahak- bahak karena MA ini tipe emosional tinggi dan berat, dan mengatakan pernah mi ku cium sama halnya dengan orang lain pacaran begitu mi juga saya. (MA, 15 tahun. 26.10.2018)"

Berdasarkan pernyataan informan tersebut maka 8 informan tersebut mengatakan hal yang terkait dengan tindakan pada disabilitas mental tuna laras MA :

“...pernah berciuman sama pacarku tapi pacar yang paling disayang ji ku suka jadi mauka cium karena kalau yang tidak disayang tidak di ciumji juga, pernah saya pegang anuku sambil terdiam dan menunduk kemudian informan mengatakan ku tauji bahayanya tapi karena biasama jadi ku anggap biasami juga, tapi begitu sering ma na marahi pak guru jadi tidak mi lagi sekarang, besok pi lagi ehhh sadar ma tidak kayak dulu. (MA.15tahun.12.10.2018)”

Berdasarkan pernyataan dari peneliti tentang perilaku seksual, 8 informan mengatakan hal yang terkait dengan persepsi dan menilai tentang perilaku seksual :

“...lamami ini nah lama mi kucerita mi pale tapi sedikit mo, waktu itu kerumahnya $\mathrm{ka}$ pacarku bawakan terang bulan ku cium ii haha sudah mi itu saja ku cerita, eh di peluk dulu baru dicium jangan maki bilang- bilang kak nah begitu memang anak gaul kak anak muda biasa anakmuda sekarang, diam diam sambil berbisik ke peneliti. Oh itu hari ku pegang anuku tidak ji kupegang saja kenapa ki kepo sekali kak...(MA. 15tahun, 14.10.2018)”, 
Setelah dilakukan wawancara secara mendalam terhadap beberapa informan dapat ada beberapa jawaban yang berbeda antara satu informan dengan informan lainnya yaitu seperti yang dikatakan dengan informan biasa atas nama MA yang mengatakan

“...bah ku tauji saya tidak boleh itu orang nakal nakal karena banyak penyakit, pernah mi ku dengar di penyuluhan tentang bahaya seks dan begitu begitu mi, tentang pencegahan penyakit supaya tidak sakit orang begitu kalau berbuat anu ki, yaa pokoknya begitu mi tapi mau mi di apa kalau pergaulan kah kita ini anak muda ki e gaul ki kak.. (MA,15 tahun, 25.10.2018)"

\section{PEMBAHASAN}

Pengetahuan atau kognitif merupakan domain yang sangat penting untuk terbentuknya tindakan seseorang, karena dari pengalaman dan penelitian terdahulu ternyata perilaku yang didasari oleh pengetahuan.

Dari hasil penelitian yang dilakukan terhadap 8 informan mengenai pengetahuan anak disabilitas mental tentang perilaku seksual bahwa ada beberapa kesamaan dari jawaban dari pihak informan atas pertanyaan-pertanyaan mengenai pengetahuan tentang perilaku seksual, meskipun tanggapan informan berbeda yang satu dengan lainnya berbeda dalam menanggapi tetapi pada intinya jawaban informan mempunyai maksud yang sama. Pengetahuan informan mengenai perilaku seksual masih ingin diberikan lebih banyak pengetahuan lagi karena ada beberapa belum paham secara mendalam tentang perilaku seksual.

Menurut peneliti pengetahuan tentang perilaku seksual kurang karena di sekolah tidak ada pembelajaran tentang perilaku seksual, kemudian di rumah orang tua belum maksimal memberikan pendidikan tentang perilaku seksual dan memperhatikan anak dan berpikir bahwa anak disabilitas tidak terlalu penting mendapatkan pendidikan perilaku seksual.

Komponen konatif merupakan aspek kecenderungan berperilaku tertentu sesuai dengan sikap yang dimiliki oleh seseorang. Dan berisi tendensi atau kecenderungan untuk bertindak/bereaksi terhadap sesuatu dengan caracara tertentu, dan berkaitan dengan objek yang dihadapinya adalah logis untuk mengharapkan bahwa sikap seseorang adalah dicerminkan dalam bentuk tendensi perilaku (Azwar, 2013).

Dilihat dari hasil penelitian terhadap 5 informan biasa, bahwa sikap yang belum mengerti etika nilai dan norma dalam pergaulan. Berbeda dengan 3 informa yang sudah bertanggung jawab terhadap penyandang disabilitas yaitu informa pendukung dan informa kunci. Sikap yang dapat dilihat dari beberapa informan yang paling mencolok pada informan pendukung yang membenarkan tentang sikap informan biasa bahwa benar memiliki pacar dan emosional yang tidak terkontrol.

Selalu ada kontroversi mengenai layak atau tidaknya pendidikan seks diberikan kepada anak-anak, sehingga orang tua ragu untuk memberikannya. Seperti yang telah disebutkan di atas, para anak tersebut dapat memperoleh informasi mengenai seks dari berbagai sumber, baik yang dapat dipercaya ataupun yang tidak dipercaya, yang bersifat baik atau bersifat menjerumuskan. Sehingga dengan pemberian informasi mengenai pendidikan seks yang tepat dari orang tua kepada anak mengenai apa yang terjadi dan apa yang mungkin terjadi dapat membantu anak untuk lebih berpikir jernih mengenai pilihan hidup mereka (Pakasi \& Kartikawati, 2013).

Dari sudut pandang kesehatan, tindakan perilaku seksual pra nikah remaja, khususnya berciuman berat dan berhubungan kelammin , menimbulkan beberapa resiko, seperti pada penelitian ini bahwa ada informan yang pernah melakukan tindakan menyimpang dan itu sangat di baik dan akan menyebabkan penyakit kelamin. Masalah yang disebut terakhir ini dapat menimbulkan masalah-masalah lainnya seperti aborsi dengan segala resikonya, tingginya sekarang angka morbiditas dan mortalitas persalinan, kelahiran bayi premature dan berat bayi yang kurang (Notoatmodjo, 2007).

Dari hasil penelitian yang dilakukan oleh peneliti pada 8 informan mendapatkan jawaban yang berbeda - beda antara satu sama lainnya mengenai tindakan perilaku seksualitas namun yang bisa dilihat dan mencolok pada tindakan yang dilakukan remaja MA yang mengatakan bahwa pernah melakukan hal yang tidak terpuji.

Menurut peneliti tindakan yang dilakukan oleh remaja ini karena kurang pengawasan dari orang terdekat, remaja bergaul dan mendapatkan lingkungan yang tidak seharusnya dia lewati 
apalagi di usia remaja, remaja mengalami yang namanya puber itu yang biasa di sebut rasa ingin tahu yang tinggi. Hal seperti ini harus ditekankan kepada guru dan keluarga agar lebih memperhatikan anak berkebutuhan khusus.

Penelitian ini membahas tentang persepsi kelompok disabilitas terhadap perilaku seksualitas di SLBN Pekkabata Polewali Mandar Sulawesi Selatan. Secara umum pendidikan seks berguna untuk memamahami nilai-nilai yang berpusat pada naluri seks yang timbul dan merupakan pengalaman normal manusia (Azis). Para penyandang disabilitas umumnya berangkat dari lingkungan keluarga yang beraneka ragam keadaan dan status sosialnya. Sehingga karakteristik dari anak - anak juga bervariasi.

Pentingnya orang tua memberikan pendidikan seks baik itu seputar informasi seksualitas maupun kesehatan reproduksi , hal itu disebabkan karena orang tua pihak yang paling dekat dan mempunyai banyak waktu dengan anak. Selain itu orang tua yang memahami kondisi dan kebutuhan anak terutama dalam tahap perkembangan seksualnya. Oleh karena itu sangat tepat jika pendidikan seks pada anak pada kelompok disabilitas dimulai dari keluarga dan dilakukan oleh orang tua. Dikutip dari penelitian (Brener dan Mattson, 2016) di dalam pendidikan seksualitas anak pada keluarga hanya membutuhkan sebuah program "Talking Parents, Healthy Teens", bertujuan untuk mempengaruhi kemampuan orangtua dalam mengkomunikasikan pada anak, pemantauan, dan keterlibatan mereka untuk berbicara tentang seks .Anak dengan kelompok disabilitas yang secara fisik sempurna dan yang menjadi pembeda mereka terbatas dalam beraktivitas seperti tunadaksa sehingga mereka rentan dengan kejahatan seksual yang sering marak terjadi. kehadiran seseorang yang akan melecehkan mereka bahkan juga ketidakmampuan mereka akan di manfaatkan oleh penjahat seksual untuk memperdayanya. Oleh karena itu maka sangat perlu bagi orang tua untuk memberikan pendidikan seks pada anak dengan kelompok disabilitas sedini mungkin.

Dari hasil penelitian yang di dapatkan pada 8 informan mengenai aktivitas seksual beresiko dan bagaimana cara menilainya bahwa pada saat remaja mengalami masa pubertas, remaja cenderung fokus pada bentuk tubuhnya dan memiliki keyakinan deskriptif dan evaluatif terkait dengan penampilan yang disebut dengan citra tubuh. Setiap remaja pasti menginginkan tubuh yang sempurna, namun terdapat remaja yang tidak mendapatkan tubuh sempurna karena memiliki keterbatasan fisik, seperti yang dialami oleh penyandang tunadaksa dan tunalaras.

Menurut peneliti Lingkungan di sekitar anak usia dini memiliki peran untuk mencegah kekerasan seksual yang dapat terjadi. Salah satunya dengan membekali anak pengetahuan, nilai-nilai, sikap, dan keterampilan yang berhubungan dengan anatomi tubuh, hubungan personal, dan seksualitas atau memberikan pendidikan seksual pada anak sejak dini. Peran ini, salah satunya, dapat dipenuhi oleh guru di sekolah karena sekolah merupakan institusi formal profesional yang bisa memberikan pendidikan seksual secara terstruktur dan anak menghabiskan sebagian waktunya di sekolah.

\section{KESIMPULAN DAN SARAN}

1. Pengetahuan informan mengenai perilaku seksual adalah semakin tinggi pengetahuan kesehatan reproduksi yang dimiliki remaja maka semakin rendah perilaku seksual pranikahnya, sebaliknya semakin rendah pengetahuan kesehatan reproduksi yang dimiliki remaja maka semakin tinggi perilaku seksual pranikahnya.

2. Sikap informan mengenai perilaku seksual dapat disimpulkan bahwa semakin tinggi sikap positif (permisif) terhadap perilaku seksual pada remaja mengakibatkan smakin besar kecenderungan remaja untuk melakukan hubungan fisik yang lebih jauh dengan lawan jenis. Kemudian sikap dan perilaku seksual memiliki pegangan yang erat yang artinya semakin positif sikap remaja terhadap perilaku seksual maka semakin besar dengan intensinya untuk melakukan perilaku seksual, sedangkan remaja yang memiliki sikap yang negative terhadap perilaku seksual akan semakin kecil intensinya melakukan perilaku seksual.

3. Tindakan informan sangat berpengaruh pada perilaku seksual berdasarkan hasil penelitian yang telah dilakukan sebagian responden belum terlalu paham, dan butuh pembelanjaraan yang lanjut dari sekolah maupun dari orang tua di rumah.

4. Perilaku seksual sangat beragam . Pemicunya bisa karena pengaruh lingkungan, social budaya, penghayatan keagamaan, penerapan 
nilai-nilai, factor psikologis hingga factor ekonomi.

5. Menurut peneliti Lingkungan di sekitar anak usia dini memiliki peran untuk mencegah kekerasan seksual yang dapat terjadi. Salah satunya dengan membekali anak pengetahuan, nilai-nilai, sikap, dan keterampilan yang berhubungan dengan anatomi tubuh, hubungan personal, dan seksualitas atau memberikan pendidikan seksual pada anak sejak dini

6. Dari lima informan utama yang berisiko ada pada penyandang tuna laras yang tidak bisa mengendalikan emosinya dan termasuk derajat c1 (berat) yang melakukan perilaku seksual yang menyimpang terhadap diri sendiri.

Sedangkan saran yang diajukan pada pada penelitian ini :

1. Disarankan agar penyandang disabilitas lebih maksimal menjaga kesehatan reproduksi dan sebaiknya pekerja social mengadakan

\section{DAFTAR PUSTAKA}

Afrizal, 2017. Metode Penelitian Kualitatif, Sebuah upaya mendukung Pnelitian Kualitatif dalam berbagai Disiplin Ilmu, Edisi 1 cetakan Keempat . Rajawali Pers. Depok.

Anganthi dan Lestari. 2007. Jurnal Penelitian. Reduksi Stigma kepada penyandang disabilitas mental. Yogyakarta (http://googlejournal-reduksi-stigmakepada-penyandang-disabilitasmental.htmldi akses pada tanggal 01.Nov.2018)

Anjali Sastry. 2014. Parenting dengan Autisme. Pustaka Pelajar. Yogyakarta.

Anonim. 2013. Pengertian kesehatan Reproduksi Remaja (http://wwwberitaterkinionline.com di akses pada tanggal 22.okt.2018)

Arisanti M, D. 2005. Perilaku seksual Remaja Retardaasi Mental (Study Deskriptif pada SLB-C Pembina tingkat malang di Lawang). Fakultas Psikologi Universitas Muhammadiyah Malang. penyuluhan tentang kesehatan reproduksi remaja agar lebih meningkatkan pengetahuan , sikap dan perilakunya dalam menjaga kesehatan reproduksi.

2. Pemerintah dan system pelayanan masyarakat harus memahami penyandang disabilitas tubuh, kebutuhannya terutama kesehatan seksual dan reproduksi yang sedikit berbeda dari orang normal dan sebaiknya dikembangkan pengetahuan seksual bagi para penyandang disabilitas mental.

3. Perlu adanya penyuluhan untuk lebih meningkatkan pengetahuan penyandang disabilitas mental tentang masalah yang berhubungan dengan kesehatan reproduksi.

4. Diharapkan kepada SLBN agar mengadakan penyuluhan kesehatan reproduksi untuk lebih meningkatkan pengetahuan dan sikap agar perilaku penyandang disabilitas mental lebih positif.

Aswar , 2013. Sikap Manusia, Teori dan Pengukurannya. Pustaka Pelajar. Yogyakarta.

Ayu ,Prima. 2017. Jurnal Penelitian. Sikap dan perilaku retardasi mental. Jakarta.

Burhanudin. 2015. Jurnal Penelitian. Aplikasi Theory Of Planned Behavior pada Intensi Mahasiswa untuk Berwirausaha. Jurnal bisnis dan ekonomi. Vol. 6 No.1 Juni 2015. Fakultas Ekonomi Universitas Janabadra

Desi Kumalasari. 2014. Jurnal Penelitian. Hubungan pengetahuan dan sikap dengan perilaku seksual pada siswa SMK. Lampung

Dian Fitriani Arsy. 2017. Jurnal Penelitian. Falktor - factor yang mempengaruhi perilaku seksual remaja di SMPN 15 kota Cirebon Tahun 2017.

Dwi Novrianda, Hermaalinda dkk. 2016. Jurnal Penelitian. Edukasi Seksualitas/ Reproduksi anak penyandang disabilitas pada pegawai panti social menuju profeionalitas pelayanan. Fakultas keperawatan Universitas Andalas. 
Emzir. 2016. Metodologi Penelitian Kualitatif : Analisi Data/ Emzir. Rajawali Pers. Jakarta.

E.Kosasih . 2012. Cara Bijak Memahami Anak Berkebutuhan Khusus .Cet1.Bandung : Yrama Widya.Bandung. Hal : 1-5, Jurnal Psikologi Klinis dan Kesehatan Mental Volume 1, No. 02, Juni 2012 \& Choirunisa Nirahma PIka Yuniar C.

Herlena Essy Phitri, Widiyaningsih. 2013. Hubungan Antara Pengetahuan dan Sikap Penderita Diabetes Mellitus dengan Kepatuhan Diet Diabetes Mellitus di RSUD Am Parikesit Kalimantan Timur. Jurnal Keperawatan Medikal Bedah. Volume 1. Nomor 1 Mei 2013. STIKES Karya Husada Semarang.

Hermiyanty , Hasanah, H. S. 2016. implementasi pendidikan kesehatan reproduksi remaja Healthy Tadulako Journal (: 45-57)

Iin Aryuni Mardan. 2014. Jurnal Penelitian. Gambaran pengetahuan sikap dan perilaku penyandang disabilitas mental mengenaikesehatan reproduksi di panti sosial Bina daksa Wirajaya makassar.

Ircham Machfoeds, 2017. Metodologi penelitian (kualitatif dan kuantitatif). Fitramaya.Yogyakarta.

Jati Rinakri Atmaja. 2013. Pendidikan dan bimbingan anak berkebutuhan khusus. Erlangga. Yogyakarta.

Kementrian Kesehatan RI. 2014. Pusat Data dan Informasi Kementrian Kesehatan RI. Jakarta: Kementrian Republik Indonesia.

2016. Pusat Data dan Informasi Kementrian Kesehatan RI. Jakarta: Kementrian Republik Indonesia.

Kementrian Republik Indonesia. 2012. Melindungi kesehatan anak penyandang cacat. Jakarta

Kusmiran, E. 2011. Kesehatan Reproduksi remaja dan Wanita. Salemba Medika. Jakarta.
Miswanto . 2014. Jurnal Penelitian. Pentingnya pendidikan kesehatan reproduksi dan seksualitas pada remaja. (http;//www.google.journal-pentingnyapendidikan-kesehatanreproduksiremaja, dan diakses pada tanggal 20.09.2018)

Notoatmodjo, S. 2010. Ilmu Perilaku Kesehatan. Rineka Cipta. Jakarta.

.2014.

Notoatmodjo, S. 2014. Metodologi penelitian Kesehatan. Jakarta.

Nirmala, S. 2017. Promosi Kesehatan dan Pendidikan Kesehatan. Jakarta: Trans Info Media.

Nurohmah, A. 2013. Pentingnya Pendidikan Kesehatan Reproduksi sejak Dini dalam Keluarga (http://psg.uii.ac.id/index.php /RADIO/AminNurohmah.html diakses pada tanggal 4.nov.2018)

Nursalam. 2014. Metodologi Penelitian Ilmu Keperawatan. Jakarta: Salemba Medika

Pariawan . 2016. Jurnal Penelitian. Pengembangan Buklet sebagai media pendidikan kesehatan Reproduksi pada remaja Tuna Netra.

Pakasi , Kartukawati. 2013. Jurnal Penelitian. Pendidikan seks pada penyandang disabilitas. (http://oid.aci.hnuisgdka.iij.disschol di akses pada tanggal 4.nov.2018)

Prasetyo, S. 2015. Metodologi Penelitian. Jakarta.

Profil SLBN Polewali Mandar Sulawesi Barat. 2017.

2018.

Program Pascasarjana Universitas Muslim Indonesia. 2014. Pedoman Penulisan Tesis dan Disertasi Makassar.

Rosdarni. 2015. Jurnal penelitian. Pengaruh factor personal terhadap perilaku seksual pranikah pada Remaja kesmas. (http://www.who.int/reproductive- 
health/adolescebt di akses pada tanggal 8.nov.2018)

Saam, Zulfan dan Wahyuni, Sri. 2013. Psikologi Keperawatan. PT. Raja Grafindo Persada: Jakarta

Santi Darmayanti. 2015. Diabetes Mellitus \& Penatalaksanaan Keperawatan. Nuha Medika: Yogyakarta.

Seniati, S. 2013. Psikologi Eksperimen. Jakarta.

Sugiyono .2012. Metode Penelitian Kuantitatif, Kualitatif dan $R \& D$. alfabeta. Bandung

Truitje , Umboh. 2015. Jurnal Penelitian. Pendidikan dan sikap orang tua pada anak anak retardasi. (http://yuyu.anakanak$\underline{\text { retard.scholerjene87i8 }}$ di akses pada tanggal 05.nov.2018)

UU Republik Indonesia No 8 Tahun 2016 pasal 1. Tentang penyandang disabilitas mental. Jakarta

Utami. (2015). Perilaku seksual remaja disabilitas mental dengan, 0042, 114-126. https://doi.org/10.24198/share.v8i1.18122

( diakses pada tanggal 9 agustus 2018)

Yunita Wulandari. 2016. Pengaruh kepercayaan terhadap penyesuaian social penyandang tuna daksa balai rehabilitasi terpadu penyandang disabilitas (BRTPD). Universitas PGRI Yogyakarta.

Yahya , B. 2013. Use of Electronic media In health promotion: is it coast effective. Malaysia. (http://bulletinkasihatanmasyarakat/adoles ebt diakses pada tnggal 2.nov.2018)

Yusran Haskas, Suryanto, Widodo J. P. 2016. The Effect of 'Locus Of Control' on The Diabetes Mellitus Patients' Intention in Performing the DM Control. International Journal of Science: Basic and Applied Research (IJSBAR). Volume 25. No. 2 tahun 2016. Universitas Airlangga Surabaya.

Widyaastuti, 2009. Kesehatan Reproduksi. Fitra Maya, Yogyakarta.

World Health Organization .2014. Kesehatan Reproduksi Remaja. 